\title{
La aplicación del Convenio 169 de la OIT sobre pueblos indígenas y tribales y sus implicaciones en nuestra legislación interna
}

SAMUEL YONG SERRANO*

\section{RESUMEN}

El principal instrumento internacional de protección de los derechos humanos, individuales y colectivos de los pueblos indígenas y tribales es el Convenio 169 de la Organización Internacional del Trabajo, OIT, 1989. En Colombia, a pesar de estar vigente desde 1991, su aplicación por parte de las autoridades colombianas todavía genera tensiones, especialmente entre los pueblos indígenas y tribales a los que está dirigido y el Estado colombiano, motivo que ha llevado al autor de este artículo a presentar y analizar algunas de las más importantes decisiones judiciales, administrativas y legislativas que se han proferido en materias relacionadas con el Convenio, con el fin de verificar las causas que han impedido su aplicación eficaz y el pleno reconocimiento de la diversidad étnica y cultural en nuestro país.

\section{PALABRAS CLAVE}

Convenio 169, Vigencia, Aplicación, Tensiones

\section{ABSTRACT}

The main international instrument to protect human rights of indigenous and tribal people is the 169 Convention of The International Labor Organization- ILO-, 1989. Despite Of being in force in Colombia since 1991, its application from the Colombian authorities, still generates tension, especially

Abogado, egresado de la Universidad Santo Tomás, Coordinador del Módulo Político-económico y docente de la Facultad de Derecho de la Universidad Santo Tomás de Bogotá. 
between the indigenous and tribal people, for which it is directed, and the Colombian State. This motivated the author to present and to analyze through his article some of the most important judicial, administrative and legislative decisions that have been issued in matters related to the Convention. All of this in order to verify the reasons that have prevented its effective application and the full recognition of the ethnic and cultural diversity in our country.

\section{KEY WORDS}

Agreement number 169 of IWO, laws in force- Application - law enforcement-

\section{INTRODUCCIÓN}

El tratado internacional ${ }^{1}$ denominado Convenio sobre Pueblos Indígenas y Tribales, de 1989, obliga a los Estados que lo hayan ratificado a reconocer y proteger la diversidad étnica y cultural sin ningún tipo de condicionamiento. Tal normatividad es un triunfo de esos pueblos sobre las políticas de integración impuestas por los estados nacionales, quienes a través de sus legislaciones han pretendido regular sus sociedades de una manera homogénea sin tener en cuenta el derecho que tienen aquellos pueblos de permanecer diferentes, con sus propias tradiciones y costumbres. En suma, constituye un rechazo a las políticas de asimilación que destruyen la cultura, cosmovisión y cosmogonía de los pueblos indígenas y tribales.

Ese reconocimiento se traduce en la práctica en el derecho que tienen estos pueblos a tener un territorio, a mantener su propia identidad tribal o indígena, a participar en la misma medida que otros sectores de la población en las decisiones importantes que se tomen dentro del Estado del que hacen parte, a gozar plenamente de los derechos humanos (individuales y colectivos) y libertades fundamentales sin obstáculos ni discriminación, a decidir sus propias prioridades, a ser consultados cada vez que se prevean medidas legislativas o administrativas que los afecten directamente, y a controlar, en la medida de lo posible, su propio desarrollo económico, social y cultural (etnodesarrollo) ${ }^{2}$.

De conformidad con el artículo 10. del Convenio, el mismo se aplica a unos destinatarios con condiciones muy especiales: de un lado a los pueblos tribales, que se encuentren en países independientes cuyas condiciones sociales, culturales y económicas los distingan de otros sectores de la colectividad nacional, y que estén regidos total o parcialmente por sus propias costumbres o tradiciones o por una legislación especial, y de otro, a los pueblos indígenas que se encuentren en países independientes, y que se consideren como tales por el hecho de descender de poblaciones autóctonas, que habitaban dentro del territorio de los actuales estados nacionales, o en una región geográfica a la que pertenecía el país en la época de la conquista o la colonización o del establecimiento de las ac-

1 Conforme al artículo 2o. de la Convención de Viena sobre el Derecho de los Tratados entre Estados y Organizaciones Internacionales o entre Organizaciones Internacionales, aprobada por ley 406 de 1997, "se entiende por 'tratado' un acuerdo internacional regido por el derecho internacional y celebrado por escrito:

i) entre uno o varios Estados y una o varias organizaciones internacionales; 0

ii) entre organizaciones internacionales, ya conste ese acuerdo en un instrumento único o en dos o más instrumentos conexos y cualquiera que sea su denominación particular".

2 Artículos 1, 3, 6, 7 y 13 del Convenio 169 de la OIT. 
tuales fronteras estatales y que, cualquiera que sea su situación jurídica, conservan sus propias instituciones sociales, económicas, culturales y políticas, o parte de ellas.

Para la doctrina "la diferencia central entre las categorías de pueblos indígenas y pueblos tribales utilizadas por el Convenio 169 de la OIT estriba en la continuidad histórica, que aparece relacionada con la precedencia en la ocupación de un territorio determinado por parte de un pueblo frente a pueblos diferentes que llegaron posteriormente al mismo espacio geográfico. En este contexto los pueblos indígenas son aquellos que han mantenido la continuidad histórica como sociedades previas a la invasión y colonización, en tanto que los pueblos tribales se distinguen de otros sectores de la sociedad por sus condiciones económicas, sociales y culturales; así como por sus tradiciones, sistemas de gobierno o estatus legal dentro del derecho interno del Estado $^{\prime 3}$.

Este tratado ha sido tan importante para las minorías étnicas de Colombia que la Corte Constitucional ${ }^{4}$, así como el Gobierno Nacional ${ }^{5}$, lo han hecho extensivo al pueblo Rom (gitanos) de Colombia y a las comunidades negras.

El Convenio 169 de la OIT, que fue incorporado a nuestro derecho interno a través de su aprobación por el Congreso de la República mediante Ley 21 de 1991 y su ratificación por el Gobierno Nacional, es a partir de su vigencia de obligatorio cumplimiento. A pesar de ello, se escuchan voces de protesta de los pueblos indígenas, pues consideran que a sus comunidades todavía se les siguen violando derechos fundamentales protegidos por el Convenio y garantizados por el Estado colombiano.
El principal objetivo de este trabajo será, entonces, determinar en qué medida dicha legislación viene siendo aplicada en Colombia. Para ello, previamente se analizará la relación jerárquica entre el derecho internacional y el derecho interno de Colombia, y luego se estudiarán las tensiones que se generan al aplicar el Convenio 169 de la OIT en nuestro país, teniendo en cuenta los aportes de los doctrinantes y estudios de casos decididos por la jurisprudencia del Consejo de Estado, la Corte Suprema de Justicia y la Corte Constitucional Colombiana.

\section{SUPREMACÍA DE LA CONSTITUCIÓN PO- LÍTICA DE COLOMBIA SOBRE LOS TRATA- DOS INTERNACIONALES}

Una de las características del Estado moderno es su soberanía, atributo que impide a cualquier organización o persona oponerse a sus decisiones; sin embargo, debe advertirse que la interdependencia existente entre los estados conlleva a que éstos, al momento de tomar una determinación, tengan en cuenta la opinión pública nacional e internacional, pues la tendencia es que los estados se encuentren vinculados por compromisos derivados de tratados bilaterales, de adhesiones a convenios multilaterales, de la existencia reconocida y consolidada de una costumbre internacional, compromisos que si no se cumplen, comprometen la responsabilidad internacional del Estado.

Ante tales circunstancias, los estados permanentemente se enfrentan a un dilema cuando van a adoptar una decisión con base en su legislación interna que se repele o contradice con la legislación externa. ¿Qué puede hacerse cuando una ley o un acto administrativo contradice una re-

3 GÓMEZ, Dalila. Pueblo Rom (Gitanos) y el Convenio 169 de la OIT. Artículo publicado en: Taller de evaluación: Convenio 169 de la OIT, Defensoría del Pueblo, Bogotá, 2001, p. 79 y 80.

4 Corte Constitucional, sentencia C-169 de 2001, Magistrado Ponente Dr. Carlos Gaviria Díaz.

5 Resolución 022 de 1999 de la Dirección General de Comunidades Negras y Minorías Étnicas del Ministerio del Interior. 
gla de derecho internacional consuetudinario, o alguna disposición de un tratado? De acuerdo con los entendidos en la materia, los distintos sistemas constitucionales nacionales han adoptado diversas soluciones. Así, en los estados donde el poder legislativo es la autoridad suprema, los tribunales tienen que aplicar la ley establecida, aún a costa de contradecir el derecho internacional, como ocurre en Gran Bretaña, donde la legislación incompatible con un tratado debe continuar siendo aplicada hasta que sea derogada por una nueva ley ${ }^{6}$.

Otros estados consideran que los tratados tienen la misma fuerza del derecho interno, por lo cual los tratados nuevos prevalecen sobre las leyes internas o, viceversa, una ley nueva prevalece sobre un tratado anterior. Este es el sistema aplicado en los Estados Unidos de América, el cual predominó por mucho tiempo en Europa occidental ${ }^{7}$.

Otro sistema es el adoptado por las constituciones más recientes de Europa Occidental, que han predicado la primacía de los tratados sobre el derecho interno ${ }^{8}$. Este es el caso de la Constitución francesa, de la española, y de la ley fundamental de Bonn (Alemania), expresando ésta última en su artículo 25 lo siguiente:
"Las reglas generales del derecho internacional público son parte integrante del derecho federal. Tienen primacía sobre las leyes y crean directamente derechos y obligaciones para los habitantes del territorio federal".

En el caso colombiano, según algunos doctrinantes, la Constitución Política no "establece explícitamente qué lugar ocupan las normas internacionales con respecto a las normas internas" ${ }^{\prime \prime}$; empero, la jurisprudencia de la Corte Constitucional, al analizar este punto, ha proclamado la supremacía de la Constitución sobre los tratados, con excepción de los tratados sobre fronteras y los tratados que reconocen derechos humanos y prohíben su limitación en estados de excepción ${ }^{10}$, ya que ellos, como lo ha señalado la Corte Constitucional, forman parte del bloque de constitucionalidad ${ }^{11}$.

\section{UBICACIÓN Y JERARQUÍA DEL CONVENIO SOBRE PUEBLOS INDÍGENAS Y TRIBALES EN NUESTRA LEGISLACIÓN}

El Convenio sobre Pueblos Indígenas y Tribales, de acuerdo con la interpretación de la Corte Constitucional ${ }^{12}$, consagra derechos humanos, luego, forma un bloque de constitucionalidad con el resto de las normas contenidas en la Constitución, lo cual le permite imponerse a la ley. Esta supralegalidad del Convenio puede inferirse

\footnotetext{
6 VIRALLY, Michel y otros. Manual de Derecho Internacional Público, Fondo de Cultura Económica, México, 1998, p. 194.

7 Ibídem.

8 Ibídem

9 QUINTANA, Juan José, Derecho Internacional Público Contemporáneo, Ediciones Jurídicas Gustavo Ibañez C. Ltda., Bogotá, 2001 , p. 47.

10 Véanse las sentencias de la Corte Constitucional, C-400 de 1998, Magistrado Ponente Dr. Alejandro Martínez Caballero; C-582 de 1999, Magistrado Ponente Dr. Alejandro Alejandro Martínez Caballero, y C-191 de 1998, Magistrado Ponente Dr. Eduardo Cifuentes Muñoz.

11 En su sentencia C-358 de 1997, la Corte Constitucional señaló que el bloque de constitucionalidad "está compuesto por aquellas normas y principios que, sin aparecer formalmente en el articulado del texto constitucional, son utilizados como parámetros del control de constitucionalidad de las leyes. Ello bien sea porque se trata de verdaderos principios y reglas de valor constitucional, esto es, porque 'son normas situadas en el nivel constitucional', como sucede con los convenios de derecho internacional humanitario, o bien porque son disposiciones que no tienen rango constitucional pero que la propia Carta ordena que sus mandatos sean respetados por las leyes ordinarias, tal y como sucede con las leyes orgánicas y estatutarias en determinados campos".

12 Corte Constitucional, sentencia SU-039 de 1997, Magistrado Ponente Dr. Antonio Barrera Carbonell.
} 
del artículo 93 de la Constitución Nacional, el cual le otorga a los tratados y a los convenios internacionales sobre derechos humanos superioridad sobre las leyes internas, una vez entran en vigencia.

\section{TENSIONES EN LA APLICACIÓN DEL CON- VENIO DENTRO DEL ESTADO COLOMBIA- NO}

El Convenio sobre Pueblos Indígenas y Tribales, como ya se mencionó, tiene unos objetivos muy concretos: que los pueblos indígenas y tribales asuman el control de sus propias instituciones $y$ formas de vida, de su desarrollo, gocen plenamente de los derechos y libertades fundamentales sin ningún tipo de obstáculos ni discriminación, así mismo se dirige a que estos pueblos mantengan y fortalezcan sus identidades, lenguas y religiones dentro del marco de los estados en que viven; por tal razón, conmina a éstos a reconocer y proteger la diversidad étnica y cultural en sus territorios.

En Colombia, estos derechos han sido desconocidos en diversas oportunidades, por ello compartimos parcialmente lo declarado por los Pueblos Indígenas de Colombia en el sentido de que el Estado colombiano ha incumplido con la aplicación del Convenio $169^{13}$.

La primera razón de este incumplimiento, es la escasa difusión de la normatividad contenida en el Convenio entre los funcionarios del Estado encargados de aplicarlo y de velar por su implementación y cumplimiento. Así, por ejemplo, encontramos el caso de un funcionario de la Gobernación del Guainía, quien en aras de garantizar la imparcialidad política en un debate electoral que se iba a adelantar, expidió un acto administrativo (circular) dirigido a corregidores, inspectores departamentales y radio-operadores de equipos de radio del departamento donde les hacía saber que a partir de una fecha determinada quedarían prohibidas las conferencias radiales y de carácter político, así como también las charlas por radio utilizando otro idioma ajeno al castellano.

Con esta decisión se vulneró de manera evidente el artículo 10 de la Constitución Política que le da carácter oficial a las lenguas y dialectos de los grupos étnicos dentro de sus respectivos territorios. Igualmente el artículo 28 del Convenio 169 que obliga a los Estados que lo hayan ratificado a adoptar medidas tendientes a proteger las lenguas indígenas, promoviendo el desarrollo y la práctica de las mismas.

En la entidad territorial (Departamento del Guainía) donde se expidió la circular ya mencionada, que por fortuna la Corte Constitucional ordenó inaplicar en virtud de una tutela ${ }^{14}$, viven comunidades de los pueblos indígenas como los Curripaco, Puinave, Desano, Tucano, Piapoco, Piratapuyo, comunidades que se vieron directamente afectadas con esa medida, toda vez que se les prohibió expresarse en su lengua materna.

Al impedirle a los pueblos indígenas hablar en su propio idioma, se atentó contra su propia identidad y se menoscabaron sus derechos. Al respecto, la doctrina mexicana ha reiterado "...que la pérdida lingüística puede ser a veces dinámicamente más significativa para la identidad de una cultura que el hecho de ser privados de su territorio"15.

13 Véase la declaración final de los representantes de los Pueblos Indígenas reunidos durante los días 9 y 10 de agosto de 2000 para el Taller de Evaluación del Convenio 169 de la OIT. Puede consultarse en Taller de evaluación, Convenio 169 de la OIT, Defensoría del Pueblo, Bogotá, 2001, p. 113.

14 Corte Constitucional, sentencia T-384 de 1994, Magistrado Ponente Dr. Carlos Gaviria Díaz. 
El Convenio 169, la Constitución Política de CoIombia y la legislación que protege a los Pueblos Indígenas, también han sido violados por los particulares, como es el caso de la "Asociación Nuevas Tribus de Colombia", persona jurídica de carácter religioso que según la Corte Constitucional, después de analizar el informe de la Dirección General de Asuntos Indígenas del Ministerio de Gobierno, desarrolló actividades que amenazaron los derechos fundamentales del pueblo indígena Nukak-Makú, tales como el libre desarrollo de la personalidad y las libertades de conciencia y de culto, así como también sus derechos culturales; por esta razón, después de conceder sabiamente la tutela en favor de ese pueblo indígena, la Corte Constitucional ordenó a las autoridades competentes del Estado colombiano que controlaran las actividades que adelantaba la "Asociación Nuevas Tribus de Colombia" dentro del territorio de los Nukak-Makú ${ }^{16}$.

Así mismo y profundizando el análisis, puede advertirse que en ocasiones los pueblos indígenas, en ejercicio de su jurisdicción especial, han vulnerado el sistema jurídico de protección de estos pueblos.

Tal es el caso del cabildo de la comunidad indígena de El Tambo, ubicada en el municipio de Coyaima, Departamento del Tolima, quien al juzgar a uno de sus miembros por el hurto de cultivos, animales y productos agrícolas, violó el debido proceso al hacer extensiva a la familia del sindicado, la sanción que se le impone a éste de expulsarlo del territorio indígena. Esta decisión fue objeto de una tutela ${ }^{17}$ que la dejó sin efectos.

De acuerdo con el Convenio 169 los métodos utilizados por la jurisdicción indígena para repri- mir los delitos deben respetarse, siempre y cuando sean compatibles con los derechos fundamentales definidos por el sistema jurídico nacional y con los derechos humanos internacionalmente reconocidos (art. 9o., numeral 10.). Este enunciado no es más que un límite a la autonomía de las comunidades indígenas cuando se trata de juzgar a sus miembros, puesto que si bien tienen constitucionalmente el derecho a ejercer su propia jurisdicción conforme a sus valores y filosofías, los procedimientos utilizados y medidas tomadas en desarrollo de su actividad judicial -por muy válidos y reconocidos que sean dentro de su comunidad- no pueden conculcar los derechos fundamentales del país del que forman parte, ni tampoco los derechos humanos reconocidos universalmente.

De otra parte, la interpretación del Convenio por parte de nuestros legisladores y los máximos tribunales de justicia no siempre ha sido afortunada, sobre todo cuando le dan un alcance restringido a las normas del tratado.

Por ejemplo, la ley 48 de 1993, en su artículo 27, numeral b), eximió de prestar el servicio militar a "los indígenas que residan en su territorio y conserven su integridad cultural, social y económica".

Considero que esta ley desconoce el artículo 10., numeral 20. del Convenio, el cual dispone: "la conciencia de su identidad tribal o indígena deberá considerarse un criterio fundamental para determinar los grupos a los que se aplican las disposiciones del Convenio". Al obligar a prestar el servicio militar a aquellos indígenas que no se encuentren en el territorio de su comunidad, se vulnera la norma mencionada y el concepto antropológico que define al indígena, pues se hace depender el derecho a ser integrante de una comunidad de un

15 ESTEVA FABREGAT, Claudio, Los derechos humanos, una forma de la dialéctica. Artículo publicado en: Pueblos indígenas y derechos étnicos, VII Jornadas Lascasianas, Universidad Nacional Autónoma de México, México, 1999, p. 48.

16 Corte Constitucional, sentencia T-342 de 1994, Magistrado Ponente Dr. Antonio Barrera Carbonell.

17 Corte Constitucional, sentencia T-254 de 1998, Magistrado Ponente Dr. Eduardo Cifuentes Muñoz. 
hecho (el estar localizado dentro de un espacio geográfico), y no de la voluntad y conciencia de querer pertenecer a un pueblo.

Lamentablemente la Corte Constitucional declaró exequible la norma comentada señalando que "para estos solos efectos del servicio militar se protege no al indígena individualmente considerado sino al indígena en un contexto territorial y de identidad determinado. Por esa vía se concluye que la protección introducida por la ley se dirige a la comunidad étnica. El mensaje final de la norma es un estímulo para que el indígena continúe perpetuando su especie y su cultura. Esto explica la doble exigencia establecida por la ley para eximir del servicio militar puesto que la finalidad de la misma es la de proteger al grupo indígena como tal, y por ende proteger a los indígenas que vivan con los indígenas y como los indígenas"18.

Estos argumentos, aunque muy loables, no los compartimos, pues se está dando primacía a un elemento material, como es el territorio, para perpetuar la especie y cultura de las comunidades indígenas, dejando de lado el elemento espiritual, que tal vez es el más importante para cumplir el cometido que señala la Corte, como quiera que verdaderamente lo que afianza y evita que los pueblos se desintegren es el querer de sus miembros de seguir reconociéndose como integrantes del mismo, pues no en vano tienen un pasado histórico en común que hace que el vínculo del miembro con el grupo sea difícil de romper.

El pronunciamiento de la Corte desconoce la realidad del país, pues muchos integrantes de estas comunidades han tenido que desplazarse de los territorios que habitan debido a las amenazas por parte de los grupos armados que existen en Colombia ${ }^{19}$. Esta salida forzada, que puede durar meses o años, no puede llevar a la pérdida del derecho de seguir siendo indígena, puesto que se puede mantener la identidad así no se viva en el lugar donde se nace.

La dificultad en la aplicación del Convenio también obedece a la disparidad de criterios que frente a la interpretación de algunas de sus normas tienen las altas cortes en sus fallos. En efecto, la Corte Constitucional, al decidir una tutela impetrada por el Defensor del Pueblo contra el Ministerio del Medio Ambiente y la sociedad Occidental de Colombia Inc., considero que se había incumplido el Convenio al no consultarse a la comunidad $U$ 'wa sobre el otorgamiento de una licencia ambiental a la mencionada sociedad para que ésta pudiera realizar actividades de prospección sísmica del Bloque Samoré. Por el contrario, el Consejo de Estado, al analizar la misma situación, resolvió la demanda de nulidad contra el acto administrativo que concedió la susodicha licencia señalando que el requisito de consulta previa a la comunidad U'wa si se había cumplido.

En esa ocasión, la Corte Constitucional, después de analizar la normatividad del Convenio relacionada con el tema de la consulta y los hechos objeto de la tutela, concluyó que cuando no sea posible el acuerdo o la concertación, la decisión de la autoridad debía estar desprovista de toda arbitrariedad y autoritarismo; por tanto la misma debía ser objetiva, razonable y proporcionada a la finalidad constitucional que le exige al Estado

18 Corte Constitucional, sentencia C-058 de 1994, Magistrado Ponente Dr. Alejandro Martínez Caballero.

19 Según el Defensor Delegado para los Indígenas y las Minorías Etnicas, Gabriel Muyuy Jacanamejoy, entre enero y julio de 2003 "han sido asesinados 118 dirigentes indígenas y se han desplazado 2531 indígenas con sus familias, lo que demuestra la vulnerabilidad que afrontan algunas comunidades como los Kankuamos, en la Sierra Nevada de Santa Marta, y los Embera-Chamí en Riosucio, Caldas, entre otros" (noticia titulada "Defensoría exige respeto por los derechos de poblaciones indígenas colombianas", publicada en la página oficial de la Defensoría del Pueblo: www.defensoria.org.co). 
la protección de la identidad social, cultural y económica de la comunidad indígena. Así mismo, señaló que el acontecimiento de informar o notificar a una comunidad indígena sobre un proyecto de exploración o explotación de recursos naturales no puede equipararse a una consulta, pues para que ésta efectivamente se dé, es menester que se presenten fórmulas de concertación o acuerdo con la comunidad así como también que ella manifieste a través de sus representantes autorizados, su conformidad o inconformidad, pues con dicho proyecto podría verse afectada su identidad étnica, cultural, social y económica. Por ello, consideró que de las reuniones celebradas con los $U$ 'wa no se podía inferir que existió la consulta requerida para autorizar la mencionada licencia ambiental, además de que la consulta debía ser previa a la expedición de ésta y por consiguiente, actuaciones posteriores a su otorgamiento destinadas a suplirla carecían de todo valor y significación ${ }^{20}$.

El Consejo de Estado, tuvo una posición diferente, pues consideró que la licencia ambiental otorgada a la Sociedad Occidental de Colombia Inc. estuvo precedida de la consulta previa, como se desprende del mismo acto acusado y de las pruebas recolectadas dentro del proceso. Consideró la Sala Plena de ese alto tribunal que la "finalidad de llegar a un acuerdo o lograr el consentimiento acerca de las medidas propuestas" 21 no puede entenderse como la exigencia absoluta de ese acuerdo o consentimiento, pues como ya había señalado al negar la solicitud de suspensión provisional del acto acusado, se trata simplemente de una finalidad, objetivo o logro que debe buscarse en las consultas, y no necesariamente que ellas entrañen un acuerdo o consentimiento de las comunidades, pues de lo contrario se estaría contraviniendo uno de los principios básicos del Estado democrático, como es el de que las autoridades legítimas están facultadas para adoptar por sí mismas las decisiones que emanan de sus respectivas competencias.

Con fundamento en lo anterior, la jurisdicción de lo contencioso administrativo decidió dejar vigente el acto administrativo que otorgó la licencia y levantó la orden de inaplicación del mismo ordenada anteriormente por la sentencia que tuteló los derechos del pueblo U'wa.

Esta diferencia de conceptos de las altas Cortes al analizar la norma del Convenio que ordena la consulta, en el caso que acabamos de comentar, además de generar confusión e inseguridad jurídica, -pues no se alcanza a entender cómo los Magistrados de la Jurisdicción Contencioso Administrativa se apartaron del estudio realizado por los Magistrados de la Jurisdicción Constitucional- contribuyó a que las normas del convenio, que son de obligatorio cumplimiento, se quedaran en letra muerta. En efecto, pues mientras que para unos debía aplicarse para los otros no. Lástima que la decisión de la Corte Constitucional no hubiese sido de aquellas que tuvieran carácter definitivo, pues era claro, que en el otorgamiento de la licencia ambiental a la sociedad Occidental de Colombia Inc., para llevar a cabo actividades de prospección sísmica del Bloque Samoré, no se consultó previamente al pueblo U'wa. Esta razón era más que suficiente para haber declarado la nulidad del acto administrativo que concedió la susodicha licencia, pues era francamente violatoria de una ley vigente, como lo es el Convenio, el cual obliga a los Gobiernos a consultar a los pueblos indígenas y tribales cuando se vayan a tomar medidas administrativas o legislativas que los afecten (artículo 6o).

20 Corte Constitucional, sentencia SU-039 de 1997, Magistrado Ponente Dr. Antonio Barrera Carbonell.

21 Consejo de Estado, Sala Plena de lo Contencioso Administrativo, sentencia S-673 del 4 de marzo de 1997, Consejero Ponente Dr. Libardo Rodríguez Rodríguez. 
Igualmente les exige crear o mantener procedimientos para consultar a estos pueblos antes de emprender o autorizar cualquier programa de prospección o explotación de recursos naturales que existan en sus territorios (artículo 15).

El conflicto entre altas cortes no sólo se ha dado entre el Consejo de Estado y la Corte Constitucional, también se ha dado entre ésta y la Corte Suprema de Justicia, como sucedió con el caso de los Embera-Katíos del Alto Sinú, quienes no fueron consultados previamente a la decisión que se tomó por parte del Gobierno Nacional para declarar de utilidad pública e interés social parte de sus tierras con el fin adelantar la construcción del proyecto hidroeléctrico Urrá I, ni tampoco antes de concederse la licencia ambiental que permitió en desarrollo de dicho proyecto trabajos de construcción de obras civiles y la desviación del río Sinú.

Fue tanto el daño que le ocasionó a esta comunidad el desarrollo de éste proyecto, que la Corte llegó a considerar la construcción de la hidroeléctrica, más perjudicial para la integridad cultural y económica del pueblo Embera-Katío del Alto Sinú que la misma presión territorial y el infrarreconocimiento a los que estuvieron sometidos desde la conquista española ${ }^{22}$. De acuerdo con las pruebas recolectadas dentro de la acción de tutela, se llegó a la conclusión que los trabajos realizados no le permitieron a este pueblo seguir conservando su economía de caza, recolecta y cultivos itinerantes, actividades que realizaron durante mucho tiempo sin destruir el medio ambiente.

Para la Corte Constitucional la expedición irregular de la licencia ambiental en el caso que estamos comentando, además de vulnerar la Carta Política en aspectos relacionados con el derecho a la participación, al debido proceso, el de la diversidad étnica y cultural y a la vida de esta comunidad, conllevó que el Estado incumpliera los compromisos adquiridos internacionalmente en materia de protección de los derechos humanos de los pueblos indígenas.

Ante este panorama y habida cuenta que de nada hubiera servido exigir que se realizara la susodicha consulta, pues ya era muy tarde para remediar los males que se habían ocasionado, la Corte Constitucional ordenó indemnizar al pueblo Embera-Katío del Alto Sinú en una cuantía que garantizara su supervivencia física, mientras se adaptaba a los cambios culturales, sociales y económicos que debía enfrentar por la destrucción de su hábitat y por ende de sus recursos alimentarios disponibles.

Para ello ordenó, en el evento de que no llegaran a un acuerdo sobre el monto de la indemnización con los propietarios del proyecto, iniciar el incidente de regulación de perjuicios ante el Tribunal Superior del Distrito Judicial de Montería (juez que había conocido en primera instancia la tutela) con el fin de que fijara el monto que se debía pagar a cada uno de los miembros del grupo durante 15 años, por concepto del subsidio de alimentación y de transporte.

Esta indemnización lamentablemente aún no se ha podido materializar por razones de procedimiento, pues la Corte Suprema de Justicia considera que "la única forma de dar cumplimiento al debido proceso en el caso específico de la liquidación de la indemnización del daño emer-

22 Corte Constitucional, sentencia T-652 de 1998, Magistrado Ponente Dr. Carlos Gaviria Díaz. 
gente ordenado en abstracto en el fallo de tutela -al igual que las de los demás perjuicios- es dando estricta aplicación al artículo 25 del decreto 2591 de 1991, por cuanto lo allí explícitamente ordenado constituye el debido proceso legal..." ${ }^{\prime 23}$.

De acuerdo con la providencia de la Sala de Casación Laboral de la Corte Suprema de Justicia, la decisión de la Corte Constitucional, además de impracticable y de haberle agregado una competencia no prevista en la ley (ser segunda instancia en el caso de la regulación de perjuicios) se aparta del decreto mencionado, al crear un procedimiento distinto, extender el plazo para regular los perjuicios de la indemnización y ordenar que el Juez que conoció la tutela en primera instancia adelante el trámite incidental. Por esta razón se abstuvo de conocer la apelación interpuesta dentro del trámite de regulación de perjuicios que adelanta el Tribunal Superior del Distrito Judicial de Montería.

Esta discusión sobre cuál debe ser el procedimiento que se debe utilizar para hacer efectiva la indemnización que se ordenó en la tutela a favor del pueblo Embera-Katío del Alto Sinú, considero que se debió haber dejado para tratarla en foros de tipo académico, pero no en este caso, donde está de por medio la vida de unas personas que fueron desplazadas de una parte de su territorio como consecuencia de la exploración del subsuelo dirigida a descubrir yacimientos petrolíferos.

Nuestros funcionarios judiciales, en situaciones como éstas donde está en juego la sobrevivencia de un pueblo, deberían ser más prácticos si desean volver realidad el objetivo principal de la administración de justicia, que es el de hacer efectivos los derechos, obligaciones, garantías y libertades consagrados en la Constitución política y la ley ${ }^{24}$. Dejar de resolver un caso alegando que no se ha dado un trámite adecuado es ir no sólo en contravía de éste cometido sino también desconocer la realidad de un pueblo, como el Embera-Katío, que está desde hace rato reclamando justicia, con el fin de hacer efectivo el derecho que tiene a recibir su indemnización por los perjuicios que se le causaron y que le permitiría seguir desarrollándose de acuerdo con su propia identidad.

A veces se esgrimen razones de soberanía para desconocer el Convenio, como puede inferirse de la demanda de tutela instaurada contra el Ministerio de Defensa Nacional y la Misión Aérea de los Estados Unidos por la instalación de bases militares norteamericanas y colombianas al interior de los predios del Resguardo de Monochoa, propiedad colectiva de los grupos étnicos Huitoto y Muinane.

Al contestar la tutela, el Ministerio de Defensa argumentó que las obras realizadas en el Resguardo mencionado hacían parte de un programa de seguridad nacional del gobierno, y por tanto, la seguridad y soberanía nacional debían primar "frente a posibles incomodidades transitorias causadas a los grupos indígenas".

No obstante que la Corte Constitucional falló la tutela a favor de las comunidades indígenas porque a su juicio se encontraba amenazado el derecho al ambiente sano de la población de Araracuara, al haberse probado que los elementos contaminantes de los manantiales de agua eran producidos por las actividades que realiza-

23 Corte Suprema de Justicia, Sala de Casación Laboral, providencia de fecha 16 de mayo de 2001, radicación No. 6620, Magistrado Ponente Dr. Fernando Vásquez Botero.

24 Recuérdese que de acuerdo al artículo 228 de la Constitución, en las actuaciones de la Administración de Justicia “prevalecerá el derecho sustancial". 
ban en el lugar los militares que operaban el radar de la Fuerza Aérea; de todas formas advierte, que los derechos de las comunidades indígenas, así se encuentren respaldados por Convenios Internacionales como el 169 de la OIT, no tienen el carácter de derechos absolutos, pues del texto de la Carta Política se deduce que ningún derecho es absoluto. De aquí que al analizar el conflicto de intereses generales que se pudiera presentar en el asunto en comento, entre los derechos de la población colombiana a su seguridad y la obligación del Estado colombiano de conservar la independencia y soberanía del territorio nacional y el derecho de la Comunidad Indígena del Medio Amazonas en cuanto a la conservación de sus valores culturales y étnicos, consideró que en ningún caso los derechos de la comunidad indígena prevalecen sobre los derechos de los colombianos, sobre todo si se tiene en cuenta que de lo que se trataba en el caso sometido a estudio era la obligación del Estado colombiano de asegurarle a los habitantes del territorio nacional la protección en sus vidas, bienes, seguridad; obligación que se cumplía instalando en diversos lugares estratégicos del territorio nacional radares para el control de aeronaves que transitan por el espacio aéreo colombiano, y específicamente para el seguimiento y persecución de aeronaves del narcotráfico. Para la Corte, por tanto, no es violatorio del derecho de propiedad el hecho de que se hubiese instalado el radar en una zona del resguardo indígena de Monochoa, Araracuara, terreno que a juicio de la comunidad indígena tiene carácter sagrado y de especial valor cultural25.

Hay eventos en los que es el órgano legislativo quien no tiene en cuenta el Convenio o le da un alcance demasiado restringido, como sucede en el caso de la ley estatutaria 649 de 2001, expedida con el fin de reglamentar el tema de la circunscripción nacional especial que permite asegurar la participación en la Cámara de Representantes de los grupos étnicos, las minorías políticas y los colombianos residentes en el exterior.

Esa ley, que era de gran importancia para los pueblos indígenas y tribales -puesto que los afectaba directamente al establecer la composición de esa circunscripción especial y determinar cuáles miembros de la comunidad pueden aspirar a representarlos en ese cuerpo colegiado-, debía ser consultada con sus destinatarios en virtud del artículo 6o., numeral 10., literal a) del Convenio sobre Pueblos Indígenas y Tribales, que impone a los Estados que lo hayan ratificado a consultar a estas comunidades cuando se tomen medidas administrativas o legislativas susceptibles de afectarlas, como es el caso que estamos comentando.

No obstante que en la expedición de esta ley se incumple con el requisito de la consulta y de que la misma Corte considera dicha consulta "conveniente y deseable", aquella es declarada exequible con el argumento de que ni la Constitución, ni el Congreso, han previsto la realización de la consulta previa cuando se adopten medidas legislativas diferentes a la explotación de los recursos naturales en los territorios indígenas ${ }^{26}$. Con este razonamiento se está desconociendo que el Convenio sobre Pueblos Indígenas y Tribales (ratificado por la ley 21 de 1991), como en muchas oportunidades lo ha declarado la misma Corte, hace parte del bloque de constitucionalidad, y por tanto, agregamos nosotros, es de obligatorio cumplimiento por parte de las autoridades del país, quienes forzosamente deben realizar la consulta correspondiente cuan- 
do tomen medidas legislativas que sean capaces de afectar a estos pueblos indígenas o tribales.

Otro tanto sucede con el decreto 1320 de 13 de julio de 1998, acto administrativo mediante el cual se reglamenta la Consulta Previa con las comunidades indígenas y negras para la explotación de los recursos naturales dentro de su territorio, donde tampoco se le dio cumplimiento a la norma del convenio anteriormente señalada. Este decreto, que fue revisado por el Consejo de Estado al resolver una acción de nulidad, se halla vigente, no obstante que entre uno de los vicios por los que se demandó se encuentra la falta de consulta previa.

Para ese alto tribunal no era necesaria la consulta previa para la expedición de ese decreto por cuanto con el mismo se están es implementando los mecanismos o procedimientos apropiados para realizar la consulta ordenada en el convenio, sin que pueda decirse válidamente que para el establecimiento de dicho procedimiento la ley exija también la consulta ${ }^{27}$, razonamiento que tampoco compartimos, pues esta medida administrativa no se podía tomar unilateralmente sin haberse discutido con las comunidades indígenas y negras, que es a quienes está dirigida y pueden resultar afectados directamente. De hecho, algunos dirigentes indígenas como Gabriel Muyuy Jacanamijoy han venido denunciado este acto administrativo, por considerar que desconoce "de manera flagrante los derechos integrales garantizados por el Convenio 169, afectando particularmente los derechos territoriales, culturales, sociales y económicos de los pueblos indígenas" ${ }^{\prime 28}$.

\section{CONCLUSIONES}

1. El Convenio sobre Pueblos Indígenas y Tribales, 1989, es una legislación que se encuentra vigente en Colombia, la cual goza en nuestro derecho interno de una jerarquía superior a la ley, ya que al consagrar derechos humanos, forma parte del Ilamado bloque de constitucionalidad. El Convenio 169 de la OIT en el contexto internacional cambió la actitud frente a la relación estados pueblos indígenas; se pasó de la política de la integración a la política de reconocimiento de la diversidad étnica y cultural de las naciones.

2. A pesar de ello, y de que uno de los principios esenciales del derecho internacional es el pacta sunt servanda, según la cual todo tratado en vigor obliga a las partes y debe ser cumplido por ellos de buena fe, se nota que el Convenio no ha sido observado en toda su plenitud en Colombia.

3. La violación del Convenio ha tenido diversas causas, la falta de voluntad política para aplicarlo, desconocimiento de su contenido, contradicciones de la jurisprudencia respecto a su interpretación, excesivo formalismo legal al resolver litigios judiciales en los que están involucradas comunidades indígenas, falta de vigilancia de los organismos del Estado encargados de controlar las actividades que realizan los particulares al interior de las comunidades indígenas.

26 Corte Constitucional, sentencia C-169 de 2001, Magistrado Ponente Dr. Carlos Gaviria Díaz.

27 Consejo de Estado, Sección Primera, sentencia 1999-5091 del 20 de mayo de 1999, Consejero Ponente Dr. Juan Alberto Polo Figueroa.

28 MUYUY JACANAMIJOY, Gabriel, Aplicación del Convenio 169 de la OIT en Colombia. Artículo publicado en: Taller de evaluación: Convenio 169 de la OIT, Defensoría del Pueblo, Bogotá, 2001, p. 24. 
4. De los casos analizados puede concluirse que se han violado los siguientes derechos otorgados por el Convenio a los pueblos indígenas: derecho al territorio, a mantener su propia identidad tribal o indígena, a gozar plenamente de los derechos humanos $y$ libertades fundamentales sin obstáculos ni discriminación, a ser consultados cada vez que se prevean medidas legislativas o administrativas que los afecten directamente, y a controlar, en la medida de lo posible, su propio desarrollo económico, social y cultural.

5. Necesidad de una nueva mentalidad. Si queremos de verdad reconocer y respetar el derecho de las minorías étnicas a ser diferentes, es hora de que empecemos a entender el cambio de paradigma que las normas del Convenio reflejan respecto a la relación tradicional que había entre la sociedad y el Estado colombiano y los pueblos indígenas. Es así, que de una política indigenista con una visión de integración política, cultural y racial hemos pasado con estas nuevas normas a reconocer y proteger la diversidad étnica y cultural de estos pueblos, donde, utilizando las palabras de Carlos Federico Marés, "se les reconoce el derecho de ser indio, de mantenerse como indio, con su organización social, lenguas, creencias y tradiciones" 29 .

Es por ello que si no empezamos a dejar atrás las viejas ideas concebidas por antiguas legislaciones de tratar a los indígenas como iguales formalmente y no como diferentes cultural e históricamente, va hacer casi que imposible aplicar el convenio en su integridad y por ende se quedará en pura retórica el derecho que tienen estas comunidades, dentro del Estado colombiano, de asumir el control de sus propias instituciones, sus formas de vida, su desarrollo económico y de mantener y fortalecer sus identidades, lenguas y religiones.

29 MARES, Carlos Federico. El Brasil constitucional y los indios. Artículo publicado en: Derechos de los pueblos indígenas en las constituciones de América Latina, Disloque Editores, Bogotá, 1996, p. 44. 